\title{
Determination of temporal changes in seismic velocity caused by volcanic activity in and around Hakone volcano, central Japan, using ambient seismic noise records
}

Yohei Yukutake $^{1 *}$ (D, Tomotake Ueno ${ }^{2}$ and Kazuki Miyaoka ${ }^{3}$

\begin{abstract}
Autocorrelation functions (ACFs) for ambient seismic noise are considered to be useful tools for estimating temporal changes in the subsurface structure. Velocity changes at Hakone volcano in central Japan, where remarkable swarm activity has often been observed, were investigated in this study. Significant velocity changes were detected during two seismic activities in 2011 and 2013. The 2011 activity began immediately after the 2011 Tohoku-oki earthquake, suggesting remote triggering by the dynamic stress changes resulting from the earthquake. During the 2013 activity, which exhibited swarm-like features, crustal deformations were detected by Global Navigation Satellite System (GNSS) stations and tiltmeters, suggesting a pressure increment of a Mogi point source at a depth of $7 \mathrm{~km}$ and two shallow open cracks. Waveforms that were bandpass-filtered between 1 and $3 \mathrm{~Hz}$ were used to calculate ACFs using a one-bit correlation technique. Fluctuations in the velocity structure were obtained using the stretching method. A gradual decrease in the velocity structure was observed prior to the 2013 activity at the KOM station near the central cone of the caldera, which started after the onset of crustal expansion observed by the GNSS stations. Additionally, a sudden significant velocity decrease was observed at the OWD station near a fumarolic area just after the onset of the 2013 activity and the tilt changes. The changes in the stress and strain caused by the deformation sources were likely the main contributors to these decreases in velocity. The precursory velocity reduction at the KOM station likely resulted from the inflation of the deep Mogi source, whereas the sudden velocity decrease at the OWD station may reflect changes in the strain caused by the shallow open-crack source. Rapid velocity decreases were also detected at many stations in and around the volcano after the 2011 Tohoku-oki earthquake. The velocity changes may reflect the redistribution of hydrothermal fluid in response to the large stress perturbation caused by the 2011 Tohoku-oki earthquake.
\end{abstract}

Keywords: Seismic velocity changes, Ambient noise, Passive image interferometry, Autocorrelation function, Hakone volcano, Earthquake swarms, Volcanic activity

\footnotetext{
* Correspondence: yukutake@onken.odawara.kanagawa.jp

${ }^{1}$ Hot Springs Research Institute of Kanagawa Prefectural Government, 586

Iriuda, Odawara, Kanagawa 250-0031, Japan

Full list of author information is available at the end of the article
} 


\section{Introduction}

To obtain information about Earth's interior, it is important to monitor temporal changes associated with the subsurface structure because seismic velocity is sensitive to stress states and rock properties (e.g., Grêt et al. 2006). Comparing coda waves from identical sources is a useful method of estimating temporal changes in seismic velocity (e.g., Snieder et al. 2002). Seismic velocity changes caused by a large earthquake or volcanic activity have been detected using the cross-correlation of seismograms of repeating earthquakes (e.g., Poupinet et al. 1984; Rubinstein and Beroza 2004; Yamawaki et al. 2004) and active control sources (e.g., Nishimura et al. 2000; Wegler et al. 2006). However, because repeating earthquakes do not occur frequently and artificial explosions are expensive, these methods often yield velocity changes with poor temporal resolution. Recently, seismic interferometry methods have been developed to obtain the Green's function between two seismic stations by using the correlation function of coda waves or ambient noise (e.g., Campillo and Paul 2003; Shapiro et al. 2005). To estimate highly resolved temporal changes in the velocity structure, the theory of seismic interferometry was applied to the auto- and crosscorrelation functions (ACFs and CCFs) for continuous ambient noise records using passive image interferometry (PII) (Sens-Schönfelder and Wegler 2006; Wegler and Sens-Schönfelder 2007).

Several studies have reported temporal changes in the velocity structure during large earthquakes obtained using PII (e.g., Wegler et al. 2009; Minato et al. 2012; Ohmi et al. 2008). Two major candidates have been proposed as mechanisms for the velocity changes before and after a large earthquake. One is a nonlinear site effect in the shallow part of the crust due to the strong ground motion occurring during the earthquake. By using the ACFs for ambient noise records, Minato et al. (2012) found a velocity decrease related to a shallow nonlinear site effect caused by the 2011 Tohoku-oki earthquake and its large aftershocks. The site effect was also demonstrated by applying a coda deconvolution method to small earthquake data recorded on the ground surface and at a borehole station (Sawazaki et al. 2009) and by investigating repeating earthquakes (Rubinstein and Beroza 2004). The other mechanism causing the temporal velocity change is the co- and post-seismic deformation in the deeper part of the crust caused by dislocation on the fault plane. Wegler and Sens-Schönfelder (2007) and Ohmi et al. (2008) reported sudden velocity decreases after the occurrence of large intraplate earthquakes based on the ACFs for the ambient noise. These studies deduced that the velocity reduction was related to coseismic stress changes in the source region of the earthquake.

In a volcanic or geothermal region, temporal changes in the subsurface structure caused by volcanic activity have also been estimated using PII. Brenguier et al. (2008) reported velocity reduction prior to the eruptions at Piton de la Fournaise volcano on La Réunion Island. Ueno et al. (2012) also observed an abrupt decrease in velocity during swarm activity in the eastern Izu Peninsula, central Japan, and the subsequent gradual recovery process. Both studies concluded that the velocity changes were related to crustal deformation caused by the intrusion of a magma body into the shallow depth region. Conversely, Maeda et al. (2010) found a localized velocity decrease during swarm activity in a geothermal region in Kyushu, Japan, and suggested that the intrusion of magmatic fluid into a deep part of the source region was the primary contributor to the localized velocity reduction. Temporal changes in the subsurface velocity structure during volcanic activity are likely controlled by several factors, such as crustal deformation and the migration of magmatic or hydrothermal fluids.

The objective of this study is to detect temporal changes in the velocity structure of Hakone volcano, where intense earthquake swarms have often occurred. Because various monitoring systems have been installed in and around the volcano, including a dense seismic observation network, geodetic observation networks such as the Global Navigation Satellite System (GNSS) operated by the Geospatial Information Authority of Japan (GSI), and tiltmeters, detailed information about earthquake swarms and deformation sources can be obtained from the dense seismic and geodetic data provided by these networks. In this study, the relationships between the temporal changes in the velocity structure and other observations, such as seismicity, crustal deformation, and strong ground motions accompanying the volcanic activity, were investigated in detail, and the main factor contributing to the velocity changes is discussed in this paper.

\section{Volcanic activity in Hakone volcano}

Hakone volcano is a caldera volcano with a diameter of $15 \mathrm{~km}$ located on the northern boundary of the Izu-Bonin-Mariana arc in central Japan. There are fumarolic areas in the Owakidani geothermal region, where the OWD station is located (Fig. 1). Intense swarm activity has occasionally occurred within the caldera of Hakone volcano, sometimes accompanied by a strong ground motion and the emergence of new fumarolic fields (Hiraga 1987; Mannen 2003). To monitor this volcanic activity, the Hot Springs Research Institute (HSRI) of Kanagawa Prefecture installed nine permanent short-period $(1 \mathrm{~Hz})$ three-component seismometers and five tiltmeters in and around the volcano (Fig. 1). Accelerographs were also installed on the ground surface at five of these stations.

The HSRI catalog indicates that approximately 17,000 earthquakes with magnitudes ranging from -1.0 to 4.8 occurred in Hakone volcano between 1 April 1995 and 31 December 2013 (Fig. 2a). In particular, intense 


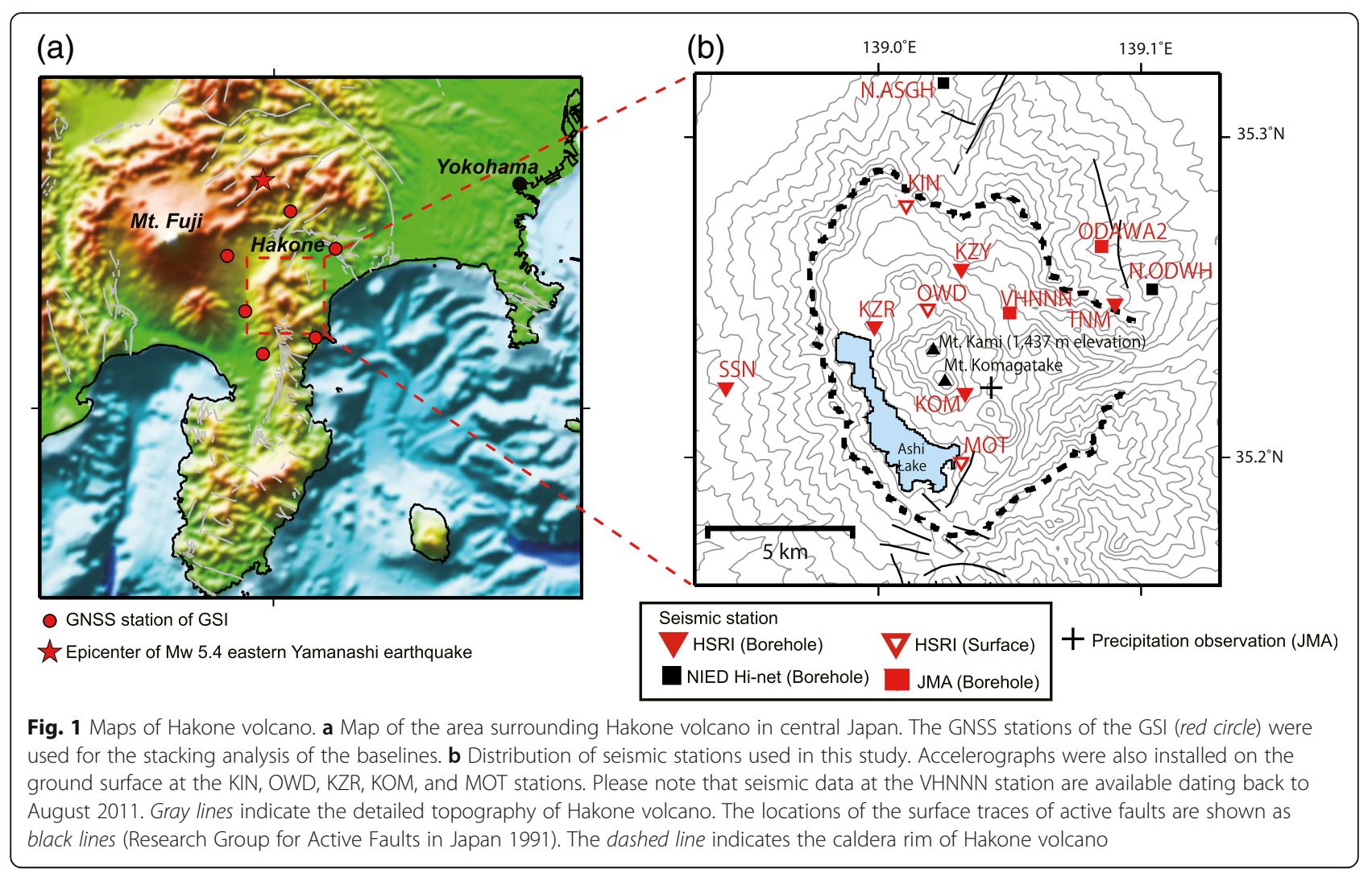

earthquake activities were observed in 2001, 2006, 2008-2009, 2011 (Fig. 2b), and 2013 (Fig. 2c). This seismic activity showed swarm-like features, except for that in 2011, and crustal expansions of several centimeters were detected by the GNSS stations (Fig. 2d) during each intense earthquake activity. During the 2001 and 2013 swarm activity, tilt changes of $1-5 \mu$ rad were also observed by the tiltmeters in the caldera.

The activity in 2011 began immediately after the passage of a surface wave from the 2011 Tohoku-oki earthquake (Mw 9.0) (Yukutake et al. 2011). The 2011 activity exhibited an Omori law-like decay rather than swarm-like features (Harada et al. 2012). The focal area of this seismic activity expanded from the northern and southern parts of the caldera (Fig. 2b). Yukutake et al. (2013) suggested that the seismic activity was triggered by the dynamic and static stress changes generated by the 2011 Tohoku-oki earthquake.

The swarm activity in 2013 started on 1 January 2013 (Fig. 3a). The focal area of this activity was concentrated around the central cone of the caldera, the Owakidani geothermal region, and Mt. Komagatake (Fig. 2c). The largest earthquake during this activity occurred beneath Owakidani at a depth of $2.0 \mathrm{~km}$ on 10 February 2013 and had a local magnitude of 2.3. A peak ground velocity of $2.8 \mathrm{~cm} / \mathrm{s}$ was observed at the OWD station during this earthquake (Fig. 3a). A tilt change of several microradians was detected starting on 10 January 2013, immediately after the beginning of the swarm activity (Fig. 3c). Additionally, Miyaoka et al. (2014) demonstrated that crustal expansion started in the beginning of October 2012, approximately 3 months prior to the onset of the swarm activity (Fig. 3b), by using a GNSS data stacking method developed by Miyaoka and Yokota (2012).

These results suggest that remarkable changes in stress, strain, or the supply of materials such as hydrothermal fluids derived from a deep magma source, occurred in Hakone volcano, accompanying the intense activity. Therefore, it is important to examine whether temporal changes in the subsurface structure associated with the volcanic activity occurred.

\section{Methods/Experimental}

Continuous velocity waveforms recorded at the HSRI, National Research Institute for Earth Science and Disaster Prevention (NIED) Hi-net, and Japan Meteorological Agency (JMA) stations were used in this study, as shown in Fig. 1. Although continuous seismic waveform data from the HSRI stations are available dating back to 1999, the seismometers and data loggers were being replaced between October 2008 and September 2010. To avoid artifact effects caused by the conversion of instrument 


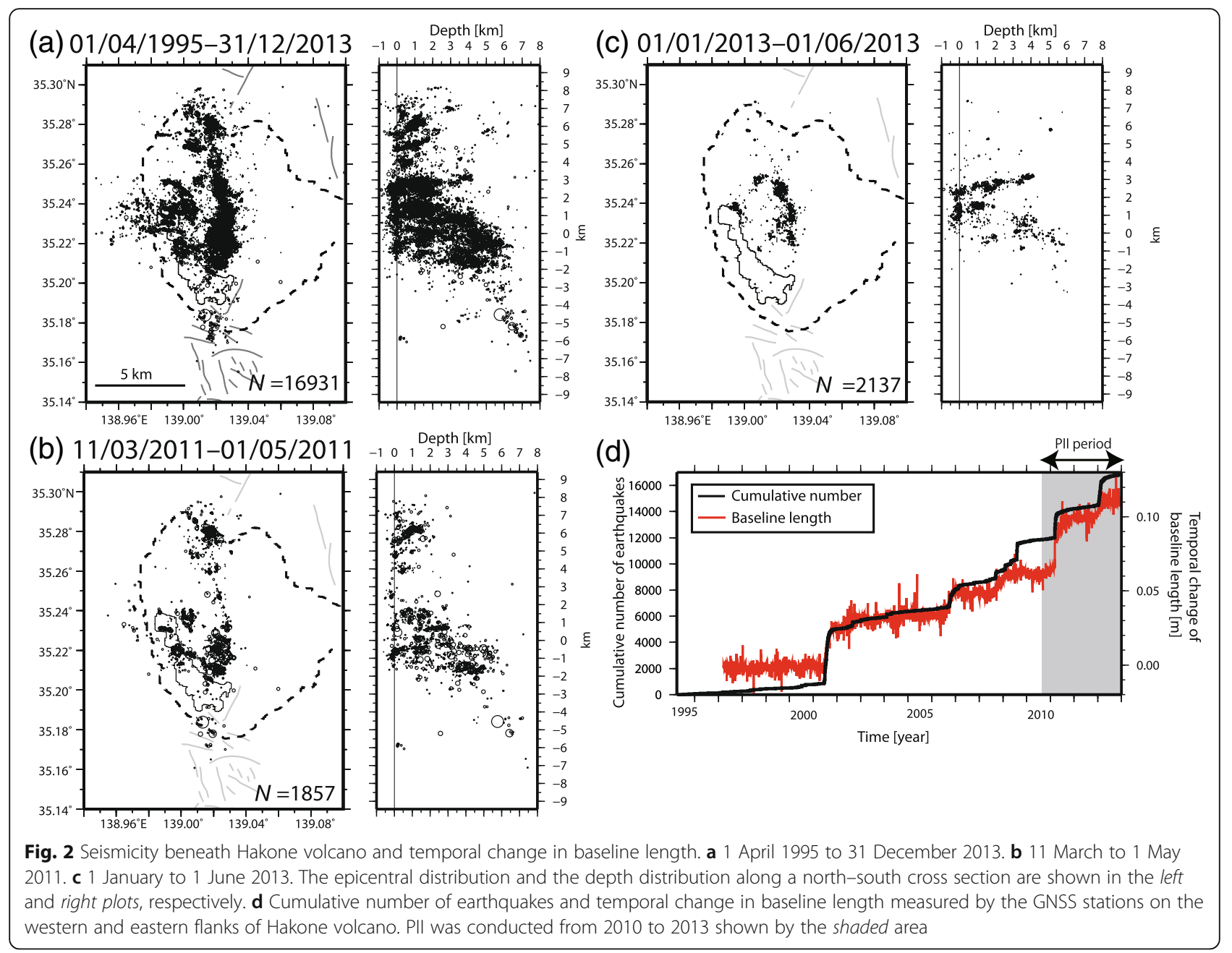

responses or dynamic ranges, our analysis focused on the seismic activity in 2011 and 2013. Vertical component waveforms from 1 October 2010 to 31 December 2013 were considered in this analysis. After removing the mean and linear trend, to obtain stable ACFs and eliminate the effect of harmonic noise around $4 \mathrm{~Hz}$ that was observed at some stations, a bandpass filter between 1 and $3 \mathrm{~Hz}$ was applied to $1 \mathrm{~h}$ waveform records. To reduce the contribution from the earthquake signals, $1 \mathrm{~h}$ ACFs were obtained using the one-bit correlation technique (e.g., Campillo and Paul 2003). Furthermore, to obtain a stable record for the ACFs, $1 \mathrm{~h}$ ACFs for 1 week time periods before the corresponding dates were stacked. Daily plots of each set of stacked ACFs estimated using the seismograms from the KOM and OWD stations are shown in Fig. 4.

The fluctuations in the velocity structure were obtained by comparing each ACF with a reference ACF using the stretching method (e.g., Sens-Schönfelder and Wegler 2006). The reference ACF trace was estimated from the mean of all ACFs in the period from 1 January
2012 to 31 December 2013. It was assumed that the medium experienced a spatially homogeneous relative seismic velocity change $\mathrm{d} v / v$. The cross-correlation coefficient between the reference ACF and the stretched or compressed ACFs was computed. The stretched or compressed ACFs were calculated as

$$
\mathrm{d} v / v=-\mathrm{d} t / t
$$

where $\mathrm{d} t$ is the time shift between a perturbation and the reference Green's function and $t$ is the lag time of the ACF. ACFs with lag times ranging from 4 to $15 \mathrm{~s}$ were used to estimate $\mathrm{d} v / v$. The lower limit of the lag time was chosen to exclude scattered waves near the receiver, and the upper limit corresponds to the time at which the amplitudes of the ACFs converged to their noise levels. A grid search was performed with $\mathrm{d} v / v$ ranging from -3 to $3 \%$ to obtain the optimal $\mathrm{d} v / v$ value that maximizes the cross-correlation coefficient between the reference and the stretched or compressed ACFs. 

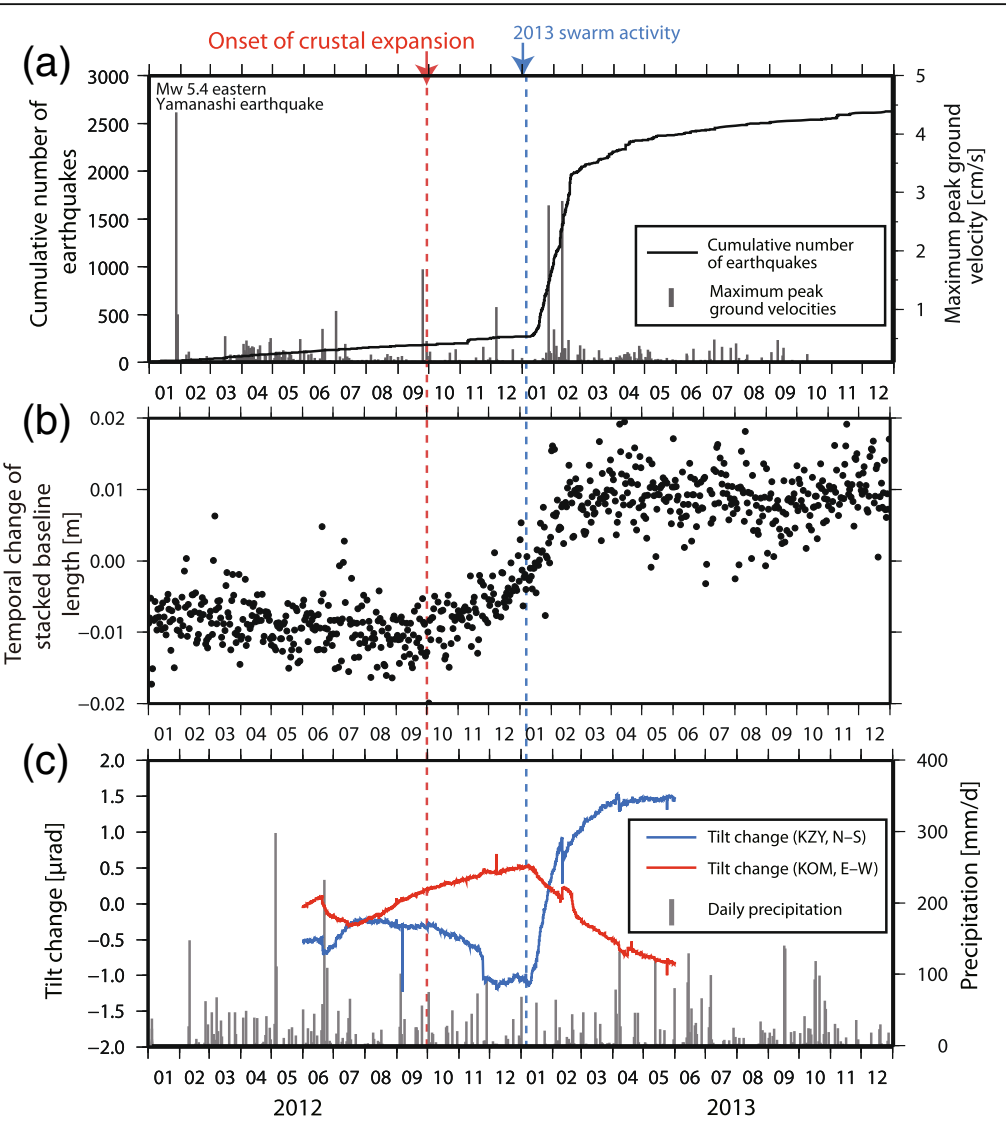

Fig. 3 Temporal changes in seismicity and other observations associated with the 2013 swarm activity. a Cumulative number of earthquakes between 1 January 2012 and 31 December 2013. The maximum peak ground velocities were measured each day at the OWD station. b Stacked baseline length of GNSS stations around Hakone volcano (Fig. 1a) obtained using the stacking method (Miyaoka and Yokota 2012). c Tilt changes measured by tiltmeters at the KZY (north-south component) and KOM (east-west component) stations. The daily precipitation rates were also plotted

The standard deviation of $\mathrm{d} v / v$ was evaluated with the cross-correlation coefficient using the following theoretical formula proposed by Weaver et al. (2011):

$$
\sigma_{d}=\frac{\sqrt{1-C C^{2}}}{2 C C} \sqrt{\frac{6 \sqrt{\frac{\pi}{2}} T}{\omega_{c}^{2}\left(t_{2}^{3}-t_{1}^{3}\right)}},
$$

where $T$ is the inverse of the frequency bandwidth; $t_{1}$ and $t_{2}$ are the lower and upper limits of the processing time window in the ACF lag time, respectively; $\omega_{c}$ is the central frequency; and $C C$ is the cross-correlation coefficient between the reference and individual ACFs.

Following the method of Ueno et al. (2012), the average $\mathrm{d} v / v$ changes before and after each seismic activity and their standard deviations were estimated. Bootstrap resampling was applied to the $\mathrm{d} v / v$ values from 1 month before to 1 month after the beginning of the activity (Table 1). Because a gradual velocity reduction was observed at the KOM station prior to the 2013 activity, as described in the following section, the average $\mathrm{d} v / v$ changes at the KOM station over different periods (1 October to 1 November 2012 and 1 June to 1 July 2013) were also estimated. Only $\mathrm{d} v / v$ values with crosscorrelation coefficients between the reference and each $\mathrm{ACF}$ trace of 0.6 or greater were used. If the number of $\mathrm{d} v / v$ values with cross-correlation coefficients less than 0.6 exceeded 15 within 1 month, the average $\mathrm{d} v / v$ value was not estimated. The difference between the $d v / v$ averages 1 month before and 1 month after the activity was calculated 2000 times for the resampled $\mathrm{d} v / v$ dataset.

\section{Results}

Figure 5a shows the temporal changes in $\mathrm{d} v / v$ at several stations during the period from 1 October 2010 to 31 December 2013. Immediately after the occurrence of the 2011 Tohoku-oki earthquake, $\mathrm{d} v / v$ was found to decrease suddenly at many stations in and around the Hakone caldera rim. These decreases in $\mathrm{d} v / v$ ranged from -1.06 to $-0.30 \%$ (Fig. 6 and Table 1). Significant changes in $\mathrm{d} v / v$ related to the 2013 swarm activity were 


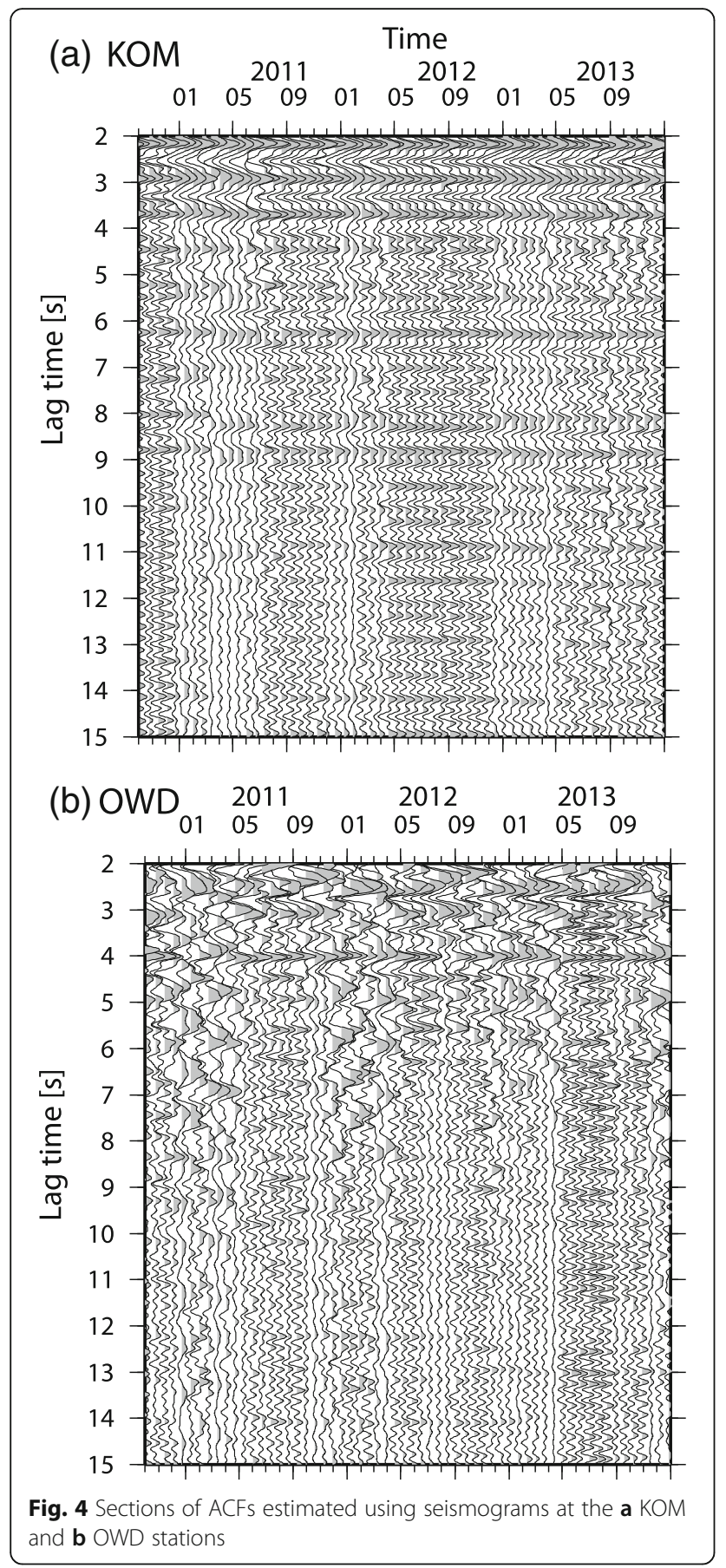

also detected at the KOM and OWD stations, which are located near the central cone of the caldera (Figs. 5 and 6 and Table 1). A significant decrease in $\mathrm{d} v / v$ was observed at the KOM station from the beginning of December 2012, preceding the 2013 swarm activity by approximately 1 month. The gradual decrease started after the onset of the stretching of the baseline length detected by the GNSS stations (Fig. 5a). The decrease in $\mathrm{d} v / v$ at the KOM station continued until the end of May 2013, and the total decrease in $\mathrm{d} v / v$ during this period was $-0.60 \%$ (Fig. $5 \mathrm{a}$ and Table 1$)$. On the other hand, a sudden decrease $(-0.65 \%)$ in $\mathrm{d} v / v$ at the OWD station was estimated to have started on 21 January 2013 (Fig. 5b and Table 1), after the beginning of the 2013 swarm activity (1 January) and the tilt changes at the KZY and KOM stations (10 January) (Fig. 3). The upper limit of the standard deviation for $\mathrm{d} v / v$ was estimated to be 0.18 \% based on Eq. (2), considering that the lower limit of the cross-correlation coefficient that can be used to estimate changes in $\mathrm{d} v / v$ is 0.6 . From this predicted error in $\mathrm{d} v / v$, it was concluded that the estimated temporal change in $\mathrm{d} v / v$ during each activity (Table 1 ) is statistically significant.

To more quantitatively investigate the dependence of the time shift $\mathrm{d} t$ on the lag time $t$ at the KOM and OWD stations, the time shift was estimated by crosscorrelating the reference ACF and the ACF for each lag time, using a time window of $1.5 \mathrm{~s}$ (Fig. 7a, b). Figure $7 \mathrm{c}-\mathrm{e}$ shows examples of the time shift as a function of the lag time on 26 March 2011 at the KOM station (for the 2011 activity), on 20 May 2013 at the KOM station, and on 20 February 2013 at the OWD station (for the 2013 swarm activity), respectively. The error in the time shift for each lag time in these figures was estimated using the bootstrap resampling method. During the 2013 swarm activity, a nearly linear relationship between the time shift and the lag time was obtained at both stations (Fig. 7d, e). After the 2011 Tohoku-oki earthquake, major phase delays were observed at the KOM station after a lag time of $7 \mathrm{~s}$ (Fig. 7c). A similar phase delay in the latter lag time was also observed at the N.ASGH station. However, because the ACFs after the 2011 Tohoku-oki earthquake were unstable, a similar trend was not observed at other stations.

\section{Discussion}

Velocity changes related to 2013 swarm activity

Significant decreases in $\mathrm{d} v / v$ related to the 2013 swarm activity were detected at the KOM and OWD stations (Figs. 5 and 6 and Table 1). The linear relationship between the time shift and lag time (Fig. 7d, e) suggests that the velocity changes were uniform in space. Several past studies reported a relationship between the decrease in $\mathrm{d} v / v$ and the volumetric strain changes caused by large earthquakes (e.g., Wegler et al. 2009; Ohmi et al. 2008) or magma intrusion (Ueno et al. 2012). Before and during the 2013 swarm activity, the crustal deformations associated with the volcanic activity were detected by the GNSS stations and tiltmeters (Fig. 3b, c). Therefore, the strain changes due to the crustal deformation sources are likely attributable to the velocity decreases.

The observed tilt vectors were used to obtain the source parameters for the deformation sources. The variation 
Table 1 Average changes in $d v / v$ and their standard deviations at each station for the 2011 Tohoku-oki earthquake and 2013 activity

\begin{tabular}{|c|c|c|c|c|c|c|c|c|c|}
\hline \multirow[t]{2}{*}{ Station name } & \multicolumn{4}{|c|}{2011 Tohoku-Oki } & \multicolumn{4}{|c|}{2013 swarm activity } & \multirow[b]{2}{*}{$P G V[\mathrm{~cm} / \mathrm{s}]$} \\
\hline & $\mathrm{d} v / v[\%]$ & SD [\%] & Term 1 & Term 2 & $\mathrm{~d} v / v[\%]$ & $\mathrm{SD}[\%]$ & Term 3 & Term 4 & \\
\hline KIN & -0.69 & 0.04 & \multirow{12}{*}{$\begin{array}{l}01 / 02 / 2011 \\
\mid \\
01 / 03 / 2011\end{array}$} & \multirow{12}{*}{$\begin{array}{l}01 / 04 / 2011 \\
\mid \\
01 / 05 / 2011\end{array}$} & 0.01 & 0.03 & \multirow{12}{*}{$\begin{array}{l}01 / 12 / 2012 \\
\mid \\
01 / 01 / 2013\end{array}$} & \multirow{12}{*}{$\begin{array}{l}01 / 02 / 2013 \\
\mid \\
01 / 03 / 2013\end{array}$} & 0.32 \\
\hline KZR & -0.35 & 0.07 & & & -0.01 & 0.10 & & & 0.45 \\
\hline$K Z Y$ & -0.30 & 0.04 & & & 0.02 & 0.02 & & & 0.36 \\
\hline MOT & -1.06 & 0.06 & & & -0.14 & 0.05 & & & 0.14 \\
\hline N.ASGH & -0.86 & 0.03 & & & -0.02 & 0.02 & & & 0.03 \\
\hline N.ODWH & -0.58 & 0.02 & & & NA & NA & & & 0.02 \\
\hline SSN & 0.14 & 0.08 & & & NA & NA & & & 0.02 \\
\hline TNM & -0.57 & 0.25 & & & NA & NA & & & 0.05 \\
\hline ODAWA2 & -0.89 & 0.17 & & & 0.03 & 0.06 & & & 0.10 \\
\hline OWD & NA & NA & & & -0.65 & 0.03 & & & 2.85 \\
\hline VHNNN & No data & No data & & & -0.08 & 0.01 & & & 0.40 \\
\hline KOM & -0.30 & 0.01 & & & $-0.15(-0.60)$ & $0.03(0.02)$ & & & 0.24 \\
\hline
\end{tabular}

The average $d v / v$ changes were estimated by subtracting the average $d v / v$ values of term 1 (or 3 ) from term 2 (or 4 ). Because a gradual decrease in the velocity was observed at the KOM station prior to the 2013 activity, the average dv/v change during the different periods (1 October to 1 November 2012 and 1 June to 1 July 2013) was also estimated, as noted in parentheses

NA not applicable

patterns for the tilt vectors observed at borehole stations during the 2013 swarm activity (Fig. 8a) were similar to those observed during the 2001 swarm activity. This result implies that similar deformation sources were displaced during each swarm activity. Using the crustal deformation data for the 2001 swarm activity, Daita et al. (2009) modeled a Mogi point source at a depth of $7 \mathrm{~km}$ based on the GNSS data and the presence of two open cracks near the surface at Owakidani and Mt. Komagatake based on the tilt vectors. The location of the Mogi point source and the locations, sizes (length and width), and orientations (azimuth and dip) of the two open cracks in 2013 were assumed to be the same as in the deformation source model for the 2001 swarm activity by Daita et al. (2009). A grid search was performed to find the optimal volume change at the Mogi point source and the two open cracks. Synthetic tilt vectors were calculated using the formula by Okada (1992). As a result, the optimal total volume change at each source was approximately a quarter of that in the 2001 source model. The variations and orientations of the observed tilt vectors at each borehole station can be mostly explained by the optimal source model (Fig. 8a).

The volumetric strain changes caused by the source model were estimated using the formula of Okada (1992). Because the delay in the ACFs was observed at an early lag time (Fig. $7 \mathrm{~d}, \mathrm{e}$ ), the relationship between the changes in the velocity and strain at a depth of $0 \mathrm{~km}$ (sea level) beneath each station was investigated. Figure $8 \mathrm{~b}$ indicates the spatial pattern of the volumetric strain changes at sea level. All of the stations used in this study are located within an area in which the volumetric strain changes were positive (dilatational). Figure 9a shows the relationship between the volumetric strain change at each station at sea level and the corresponding changes in $\mathrm{d} v / v$ for the 2013 swarm activity. The strain changes during the 2013 swarm activity exceeded $10^{-6}$ at the OWD and KOM stations. Conversely, other stations at which no remarkable decrease in $\mathrm{d} v / v$ was detected are located in areas where the dilatational strain changes were less than $10^{-6}$. It is likely that the large dilatational strain changes (exceeding $10^{-6}$ ) contributed to the decrease in $\mathrm{d} v / v$ in this region. This result is consistent with the estimations obtained in other volcanic areas, such as in the eastern part of the Izu Peninsula (Ueno et al. 2012).

However, the temporal variations in $\mathrm{d} v / v$ at the KOM and OWD stations are clearly different. The gradual decrease in $\mathrm{d} v / v$ at the KOM station started in the beginning of December 2012, after the onset of crustal expansion (Fig. 3b), whereas the sudden decrease in $\mathrm{d} v / v$ at the OWD station was observed after the onset of the 2013 swarm activity. The temporal change in the stacked baseline length (Fig. 3b) implies that the stretching of the baseline length across Hakone volcano started in the beginning of October 2012. This crustal expansion was mainly caused by the Mogi point source at a depth of $7 \mathrm{~km}$ beneath the KOM station (Fig. 8a). At the beginning of December 2012, when the velocity began to gradually decrease, the baseline seemed to have stretched by approximately $25 \%$ of its total deformation (Fig. 3b). If it is assumed that $25 \%$ of the total inflation at the Mogi point source had already occurred at that time, the area in which the volumetric strain change exceeded $10^{-6}$ is distributed only in the shallow 


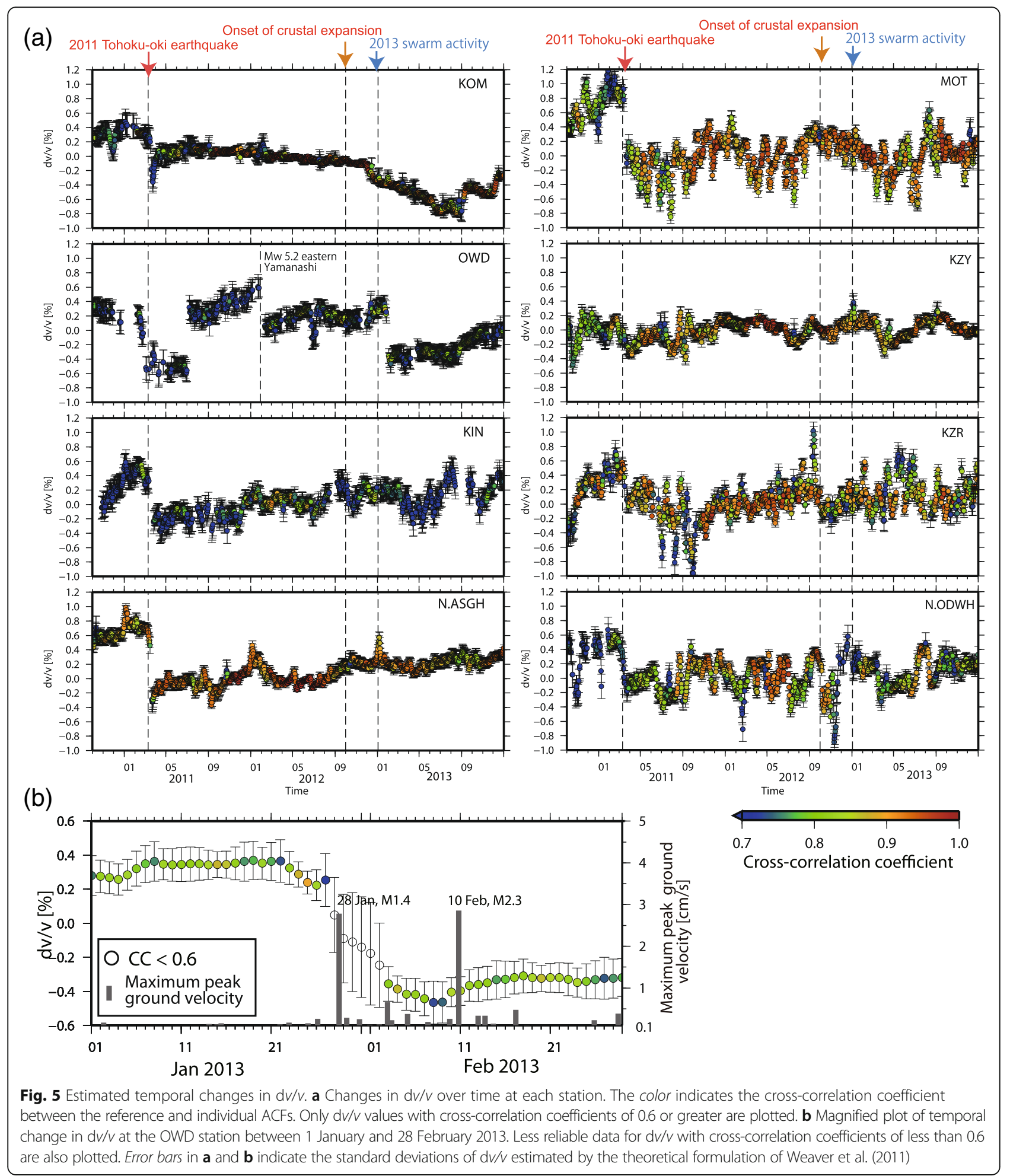

region (depth of approximately $1.5 \mathrm{~km}$ ) beneath the KOM station. The gradual velocity decrease at the KOM station may reflect the strain changes caused by the inflation of the Mogi point source that began prior to the swarm activity (Fig. 10a).
A sudden decrease in $\mathrm{d} v / v$ at the OWD station (Fig. 5) was detected after the onset of the tilt change observed at the KZY station, which is located $2 \mathrm{~km}$ northeast of the OWD station (Fig. 8a). The tilt change at the KZY station was observed starting on 10 January 2013 and 
(a) 2011 Tohoku-oki earthquake

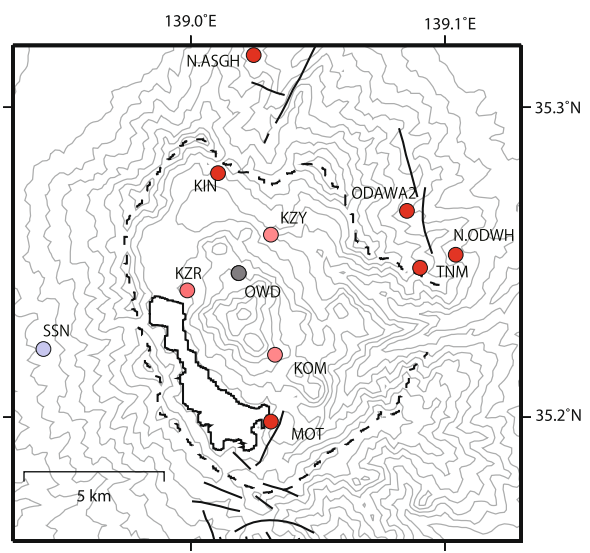

(b) 2013 swarm activity

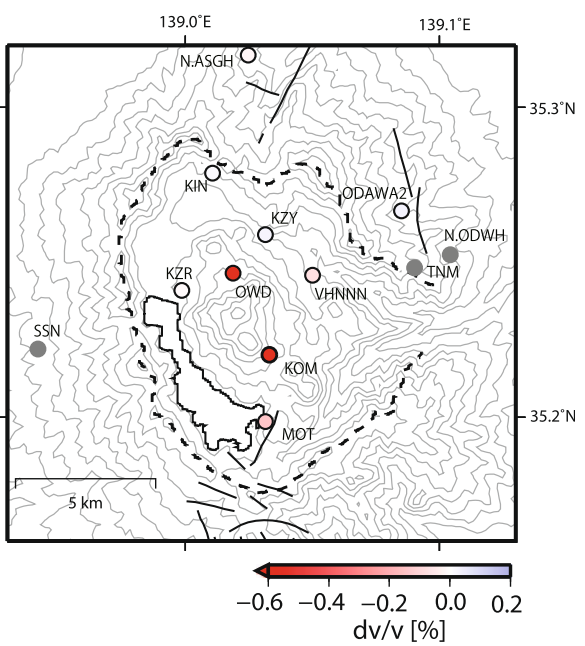

Fig. 6 Average change in $d v / v$ associated with different events. Calculated differences between the average dv/v 1 month before and 1 month after each activity for $\mathbf{a}$ the 2011 Tohoku-oki earthquake and $\mathbf{b}$ the $2013 \mathrm{swarm}$ activity. The average change in $\mathrm{d} v / \mathrm{v}$ at the KOM station during the 2013 swarm activity was calculated during the different periods (1 October to 1 November 2012 and 1 June to 1 July 2013). Stations at which the average $\mathrm{d} v / v$ changes could not be obtained because of a lack of reliable $\mathrm{d} v / v$ values (i.e., there were fewer than $15 \mathrm{~d} v / v$ values with cross-correlation coefficients of 0.6 or greater within 1 month) are colored gray

reflects the opening of the shallow crack near the OWD station (Figs. 3c and 8a). The sudden velocity decrease (Fig. 5) may have resulted from the volumetric strain change produced by the opening of the shallow crack (Fig. 10a). Honda et al. (2014) reported a noticeable decrease in anisotropic intensity at Hakone volcano based on S-wave splitting analysis during the 2001 swarm activity, and concluded that the decrease in the anisotropic intensity resulted from changes in the stress caused by the opening of the shallow cracks. The results imply that changes in the strain and stress caused by the deformation sources could be a major factor influencing the changes in the subsurface structure. However, the opening of the shallow cracks identified based on the tilt change may have allowed the intrusion of hydrothermal fluid into the shallow region. This hydrothermal fluid may have changed the seismic velocity at shallow depths. However, the precursory velocity decrease observed at the KOM station cannot be explained by fluid migration, because no evidence indicating fluid migration near the KOM station, such as shallow seismic activity or changes in tilt, was observed before the 2013 swarm activity.

The temporal changes in $\mathrm{d} v / v$ can also be explained by rainfall (Sens-Schönfelder and Wegler 2006). As shown in Fig. 3c, heavy rainfall was not observed in the Hakone region during the 2013 swarm activity. From May to July 2012, which is the rainy season in this area, rainfall exceeding $200 \mathrm{~mm}$ /day was observed several times (Fig. 3c). Even during this rainy season, changes in the velocity at the KOM and OWD stations were not observed to be coincident with the rainfall (Fig. 5a). This result indicates that the ACFs in this frequency range are not sensitive to fractional velocity changes near the surface caused by precipitation.

In addition to the effect of rainfall, a nonlinear site effect on the velocity change must be considered. A velocity decrease exceeding the standard deviation was initially detected on 2 February 2013 (Fig. 5b). A peak ground velocity of $2.8 \mathrm{~cm} / \mathrm{s}$ was observed during two earthquakes on 28 January 2013 (M 1.4) and 10 February 2013 (M 2.3), which occurred just beneath the OWD station (Fig. 5b). No significant velocity reduction was detected after the $M$ 2.3 earthquake, whereas the velocity decrease continued after the M 1.4 earthquake on 28 January 2013 (Fig. 5b). Moreover, no significant relationship was obtained between the maximum peak ground velocity and the average change in $d v / v$ during the 2013 swarm activity (Fig. 9b). These results suggest that it is difficult to interpret the sudden velocity reduction at the OWD station as being a result of a nonlinear site effect caused by an earthquake.

A sudden decrease in $\mathrm{d} v / v$ at the OWD station was also detected at the end of January 2012 (Fig. 5), corresponding to the occurrence time of a moderate-sized earthquake (Mw 5.4) (e.g., Yamada et al. 2015) that occurred in the eastern part of Yamanashi Prefecture at a depth of $18 \mathrm{~km}$ and an epicentral distance of approximately $30 \mathrm{~km}$ from Hakone volcano (Fig. 1a). During this earthquake, a peak ground velocity of $4.1 \mathrm{~cm} / \mathrm{s}$, which is larger than those observed during the 2013 swarm activity (Fig. 3a), was observed at the OWD station. No activation of seismicity or crustal deformation was observed at Hakone volcano. Although comparable 

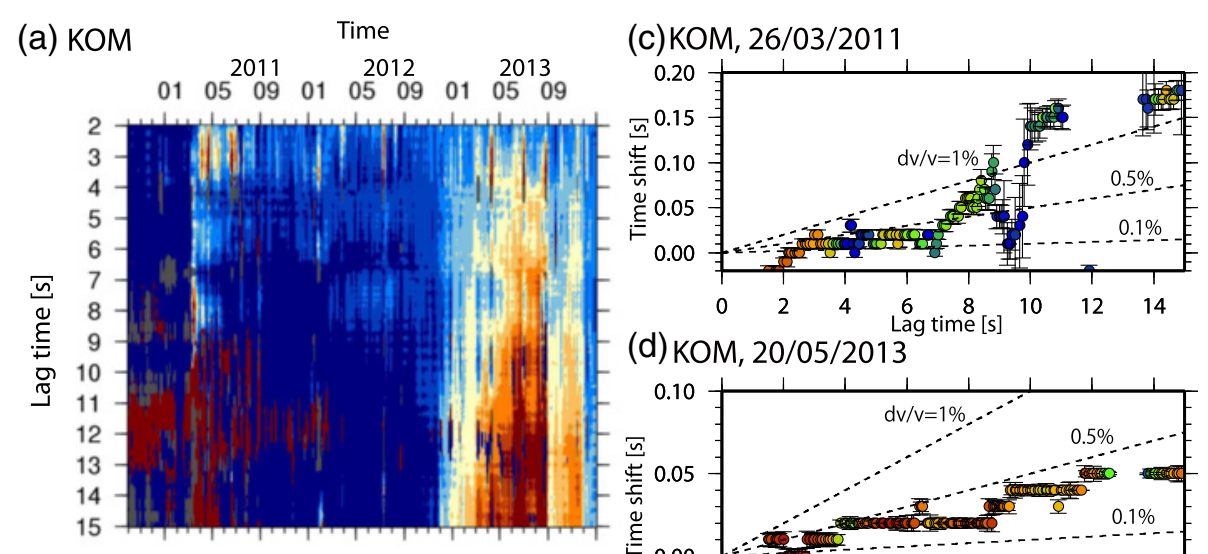

(d) KOM, 20/05/2013

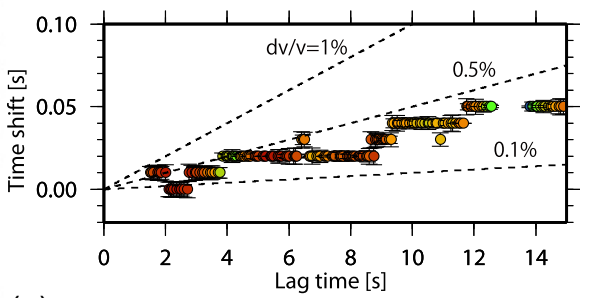

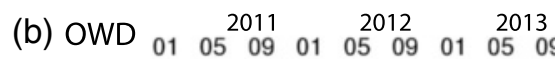

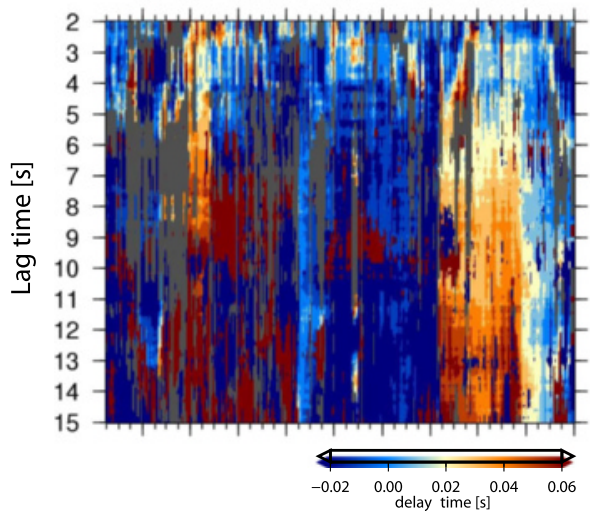

(e) OWD, 20/02/2013

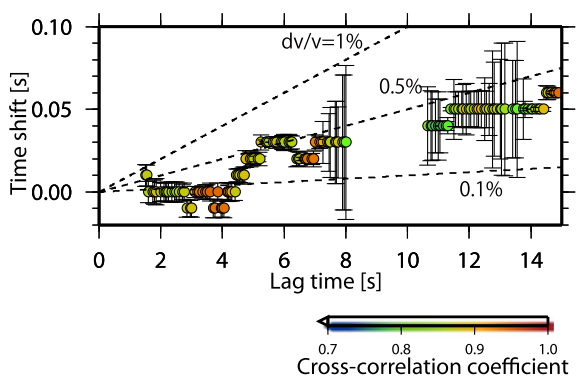

Fig. 7 Dependence of the time shift $\mathrm{d} t$ on the lag time $t$ in ACFs. $\mathbf{a}, \mathbf{b}$ Lag time and time dependence of the relative ACF phase delay at the KOM and OWD stations. Time shifts $\mathrm{d} t$ were measured by the cross-correlation of the reference ACF and each ACF with a time window of $1.5 \mathrm{~s}$. If the maximum correlation coefficient was less than 0.6, the time shift value was excluded; these values are shaded gray. Time shift as a function of lag time $t \mathbf{c}$ at the KOM station on 26 March 2011 (immediately after the 2011 Tohoku-oki earthquake), d at the KOM station on 20 May 2013 , and $\mathbf{e}$ at the OWD station on 20 February 2013 (during the 2013 swarm activity). Only dt values with cross-correlation coefficients of 0.6 or greater and standard deviations $\mathrm{dt}$ of less than $0.05 \mathrm{~s}$ are plotted

peak ground velocities were also observed at the stations near the OWD station $(3.1$ and $3.6 \mathrm{~cm} / \mathrm{s}$ at the $\mathrm{KIN}$ and KZR stations, respectively) (Fig. 1b), a significant velocity change was not detected at these stations (Fig. 5). This result may imply that the subsurface velocity structure close to the OWD station is sensitive to the changes in the dynamic stress. Because the OWD station is located near the Owakidani geothermal region, an active fumarolic area, hydrothermal fluid associated with geothermal activity likely exists near the station at shallow depths. The presence of highly pressurized fluid may be related to the high sensitivity at the OWD station. An offset in the $\mathrm{d} v / v$ values was also observed at the OWD station at the end of June 2011. Because the traces of ACFs changed at this time, especially after a lag time of $5 \mathrm{~s}$, the sudden increase in $\mathrm{d} v / v$ may have been caused by a change in the noise source around the station.

\section{Velocity decrease after 2011 Tohoku-oki earthquake}

Sudden decreases in velocity were observed at most of the stations immediately following the 2011 Tohoku-oki earthquake (Figs. 5a and 6a). The static strain changes caused by the Tohoku-oki earthquake were less than $10^{-6}$ at Hakone volcano (Harada et al. 2012). Conversely, the dynamic strain changes caused by the large-amplitude surface waves exceeded $10^{-5}$ (Yukutake et al. 2013). These large dynamic strain changes likely affected the velocity structure at Hakone volcano, given the discussion of the 2013 swarm activity. Brenguier et al. (2014) reported a similar velocity decrease after the 2011 Tohoku-oki earthquake and found that the area in which the velocity was reduced was concentrated near the active volcanoes in the eastern part of Honshu, including Hakone volcano, whereas the large strain changes 


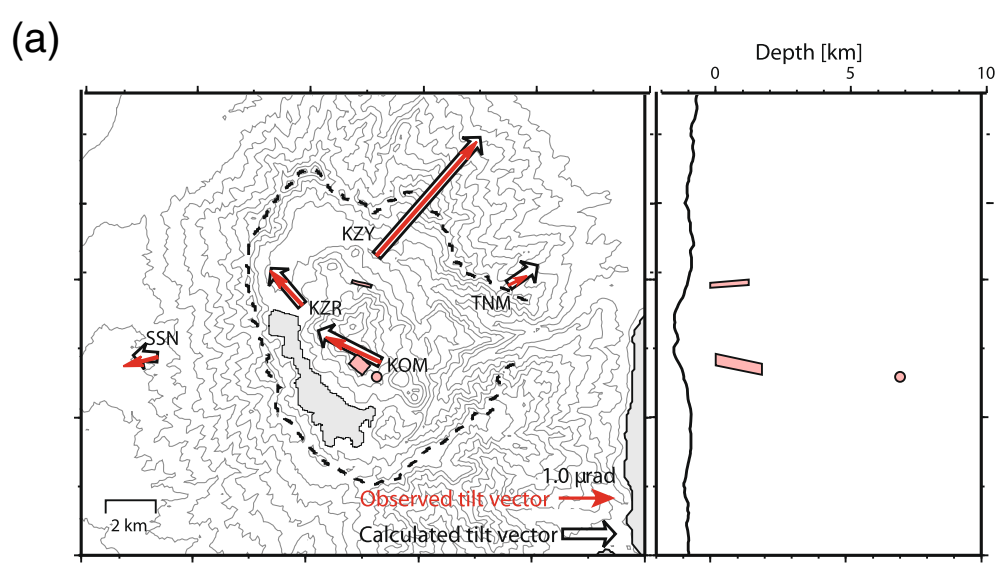

(b)

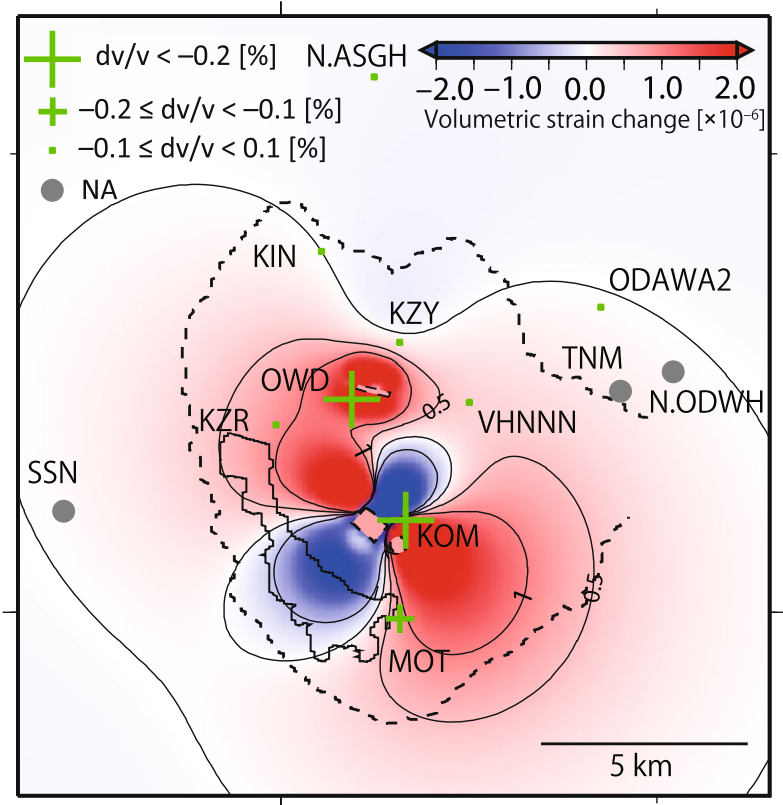

Fig. 8 Deformation sources and volumetric strain change. a Deformation sources estimated from crustal deformation data obtained during the 2013 swarm activity. The red rectangles and circle indicate the locations of the shallow open cracks and the Mogi point source at a depth of $7 \mathrm{~km}$, respectively. The white and red arrows show the observed and calculated tilt vectors at each borehole station, respectively. $\mathbf{b}$ Volumetric strain change at a depth of $0 \mathrm{~km}$ (sea level) calculated for the two shallow open cracks and the Mogi point source. Cross sizes indicate the changes in $\mathrm{d} v / v$ at each station related to the 2013 swarm activity (Fig. 6)

acted in a broad area spanning the Japanese archipelago. They determined that the velocity structure in the volcanic and geothermal regions is sensitive to stress perturbations because of the presence of hydrothermal and magmatic fluids. Hydrothermal fluid and a magma body were found to be present at depths of $3-10 \mathrm{~km}$ and greater than approximately $10 \mathrm{~km}$, respectively, under Hakone volcano using seismic tomography (Yukutake et al. 2015). Yukutake et al. (2013) suggested that the redistribution of hydrothermal fluid by large dynamic strain changes may have contributed to the initiation of the seismic activity in 2011. The velocity reductions at many stations occurred rapidly in comparison with those during the 2013 activity. A velocity reduction of up to $-1.06 \%$ was observed within 10 days after the occurrence of the Tohokuoki earthquake. The sudden velocity reductions may reflect a sudden redistribution of fluid, corresponding to the large stress perturbation from the Tohoku-oki earthquake (Fig. 10b). The phase delays after a lag time of $7 \mathrm{~s}$ at the KOM station (Fig. 7c) imply that the velocity change possibly occurred at a depth of approximately $12 \mathrm{~km}$ if the constituents of the ACFs are assumed to be backscattered S-waves (e.g., Maeda 


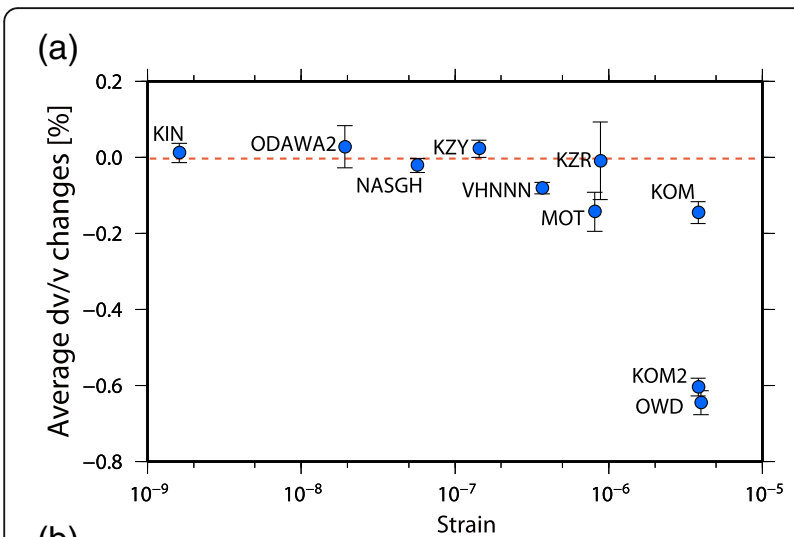

(b)

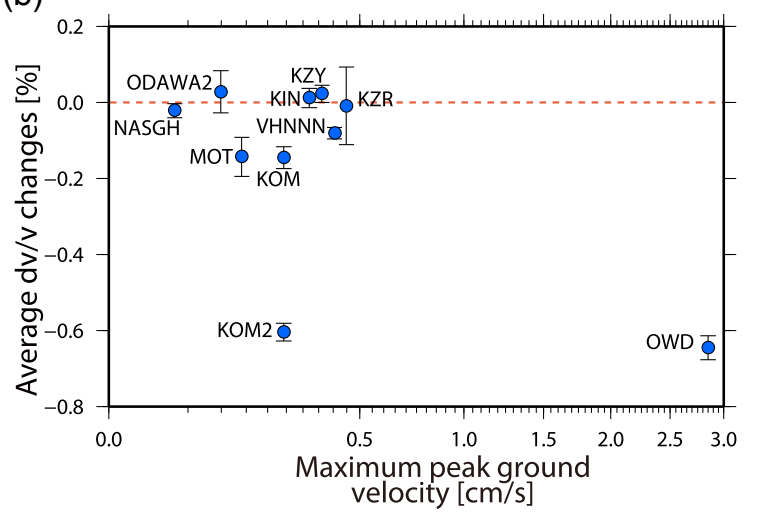

Fig. 9 Relationship between the average $d v / v$ change and other observations. Change in dv/v related to the 2013 swarm activity plotted against $\mathbf{a}$ the volumetric strain and $\mathbf{b}$ the maximum peak ground velocity during the activity. Error bars show the standard deviations of $d v / v$ estimated using bootstrap resampling (details are provided in the text). The label "KOM2" indicates the average $\mathrm{d} v / \mathrm{v}$ change at the KOM station during the different periods (1 October to 1 November 2012 and 1 June to 1 July 2013) et al. 2010). The velocity changes might have occurred mainly around the deep magma source of the volcano.

\section{Conclusions}

Through the analysis of ACFs of ambient noise, two distinct temporal changes in the subsurface structure in the Hakone volcanic and geothermal region were clearly detected during the 2013 swarm activity and after the 2011 Tohoku-oki earthquake. These two events showed different characteristics in their velocity reductions, implying different mechanisms. During the 2013 swarm activity, a sudden velocity decrease was observed at the OWD station, which is located near an open crack source. The velocity reduction started immediately after the onset of the tilt change and the swarm activity. Conversely, the velocity was found to gradually decrease at the KOM station, which is located above a Mogi point source positioned at a depth of $7 \mathrm{~km}$. The velocity decrease started before the 2013 swarm activity. The changes in the stress and strain caused by the deformation sources accompanying the volcanic activity likely contributed to the velocity changes. The precursory velocity reduction at the KOM station likely resulted from the inflation of the deep Mogi source, whereas the sudden velocity decrease at the OWD station can be explained by the strain change caused by the shallow crack source that opened 3 months after the inflation of the deep Mogi source. We eliminated the possibility that these velocity reductions were caused by precipitation or a nonlinear site effect resulting from strong ground motion. Furthermore, many stations detected significant velocity reductions in and around the caldera rim of Hakone volcano immediately after the 2011 Tohoku-oki earthquake. This result indicates that the velocity reduction occurred in a wide area in and around the Hakone caldera. It was concluded that the velocity changes reflect the fluid redistribution caused by changes in the dynamic stress due to the seismic waves associated with the 2011 Tohoku-oki earthquake. The different types of

\section{(a) 2013 swarm activity}

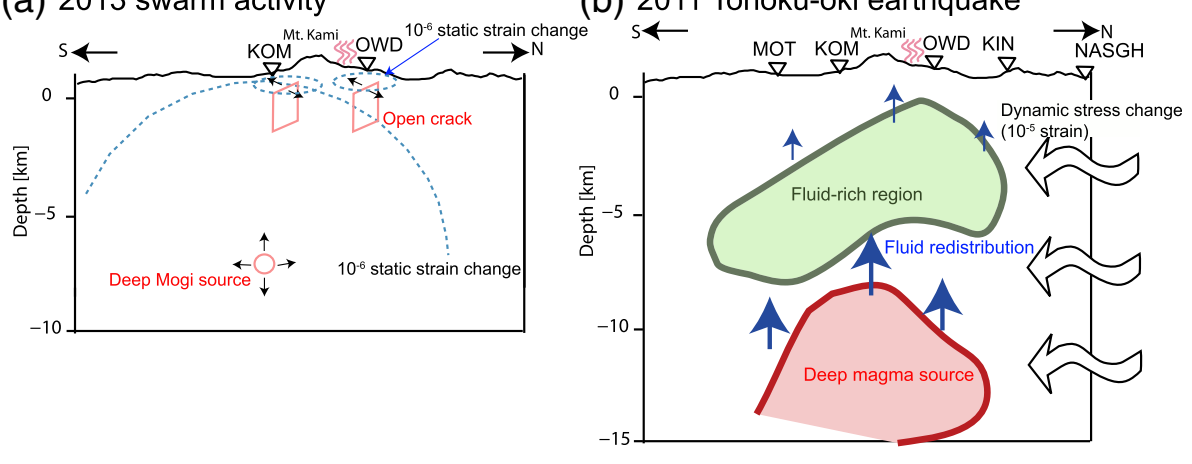

(b) 2011 Tohoku-oki earthquake

Fig. 10 Schematic of mechanisms causing velocity reductions. a During the 2013 swarm activity and $\mathbf{b}$ after the 2011 Tohoku-oki earthquake. White triangles indicate the locations of seismic stations. The locations of the deep magma body and the fluid-rich region revealed by the seismic tomography (Yukutake et al. 2015) are included in (b) 
velocity changes are important observations to discuss the response system for changes in the strain and stress in volcanic and geothermal regions. The results of this study also indicate that PII can be used to detect small changes in the stress and strain states caused by volcanic activity with high temporal resolution. Therefore, the application of this technique to monitor fractional changes in the velocity structure would be useful in volcanic hazard assessments.

\section{Abbreviations}

ACF: Autocorrelation function; CCF: Cross-correlation function; GNSS: Global Navigation Satellite System; GSI: Geospatial Information Authority of Japan; HSRI: Hot Springs Research Institute; JMA: Japan Meteorological Agency; NIED: National Research Institute for Earth Science and Disaster Prevention; PII: Passive image interferometry

\section{Acknowledgements}

We used seismic waveform data observed at the NIED Hi-net and JMA stations and GNSS data obtained by GSI stations. We greatly appreciate the helpful comments given by Dr. Takuo Maeda and Dr. Tatsuhiko Saito. We are thankful to the three anonymous reviewers and Editor Hitoshi Kawakatsu, who greatly helped us improve this manuscript. The authors would like to thank F. Waldhauser for providing the hypoDD code. JMA provided precipitation data at Hakone volcano.

\section{Funding}

This work was partly supported by a MEXT Grant-in-Aid for Scientific Research (C) 25400450 (MM) and JSPS KAKENHI Grant Number 15K17755.

\section{Authors' contributions}

YY analyzed the data and wrote the manuscript. TU assisted with the interpretation. MK estimated the source model for the 2013 swarm activity using geodetic data. All authors read and approved the final manuscript.

\section{Competing interests}

The authors declare that they have no competing interests.

\section{Author details}

${ }^{1}$ Hot Springs Research Institute of Kanagawa Prefectural Government, 586 Iriuda, Odawara, Kanagawa 250-0031, Japan. ${ }^{2}$ National Research Institute for Earth Science and Disaster Prevention, Tsukuba, Ibaraki 305-0006, Japan. ${ }^{3}$ Meteorological Research Institute, 1-1 Nagamine, Tsukuba, Ibaraki 305-0052, Japan

Received: 29 March 2016 Accepted: 1 September 2016

Published online: 27 September 2016

\section{References}

Brenguier F, Shapiro NM, Campillo M, Ferrazzini V, Duputel Z, Coutant O, Nercessian A (2008) Towards forecasting volcanic eruptions using seismic noise. Nat Geosci 1(2):126-130. doi:10.1038/ngeo104

Brenguier F, Campillo M, Takeda T, Aoki Y, Shapiro NM, Briand X, Emoto K, Miyake H (2014) Mapping pressurized volcanic fluids from induced crustal seismic velocity drops. Science 345(6192):80-82. doi:10.1126/science.1254073

Campillo M, Paul A (2003) Long-range correlations in the diffuse seismic coda. Science 299(5606):547-549. doi:10.1126/science.1078551

Daita Y, Tanada T, Tanbo T, Ito H, Harada M, Mannen K (2009) Temporal change of the pressure source estimated by tilt records during the 2001 Hakone swarm activity. B Volcanol Soc Jpn 54(5):223-234 (in Japanese with English abstract)

Grêt A, Snieder R, Scales J (2006) Time-lapse monitoring of rock properties with coda wave interferometry. J Geophys Res 111 (B3). doi:10.1029/2004JB003354

Harada M, Aketagawa T, Ito H, Honda R, Yukutake Y, Itadera K, Yoshida A (2012) Swarm activity in Hakone volcano induced by the 2011 off the Pacific Coast of Tohoku Earthquake. J Seismol Soc Jpn 2nd ser 64:135-142 (in Japanese with English abstract)

Hiraga S (1987) Seismicity of Hakone volcano and its adjacent area. B Hot Springs Res I Kanagawa Pref 18:149-273 (in Japanese)

Honda R, Yukutake Y, Yoshida A, Harada M, Miyaoka K Satomura M (2014) Stressinduced spatiotemporal variations in anisotropic structures beneath Hakone volcano, Japan, detected by S wave splitting: a tool for volcanic activity monitoring. J Geophys Res 119(9):2014JB010978. doi:10.1002/2014JB010978

Maeda T, Obara K, Yohei Y (2010) Seismic velocity decrease and recovery related to earthquake swarms in a geothermal area. Earth Planets Space 62(9):685-691. doi:10.5047/eps.2010.08.006

Mannen K (2003) A re-examination of Hakone earthquake swarms by literature (1917-60): implications for the regional tectonics. B Volcanol Soc Jpn 48(6):425-443 (in Japanese with English abstract)

Minato S, Tsuji T, Ohmi S, Matsuoka T (2012) Monitoring seismic velocity change caused by the 2011 Tohoku-oki earthquake using ambient noise records. Geophys Res Lett 39(9):L09309. doi:10.1029/2012GL051405

Miyaoka K, Yokota T (2012) Development of stacking method for the detection of crustal deformation: application to the early detection of slow slip phenomena on the plate boundary in the Tokai region using strain data. J Geol Soc Jpn 65:205-218. doi:10.4294/zisin.65.205 (in Japanese with English abstract)

Miyaoka K, Harada M, Doke R (2014) Monitoring of crustal deformation by GNSS data with applying the stacking method. B Hot Springs Res I Kanagawa Pref 46(1-8) (in Japanese with English abstract)

Nishimura T, Uchida N, Sato H, Ohtake M, Tanaka S, Hamaguchi H (2000) Temporal changes of the crustal structure associated with the M6.1 earthquake on September 3, 1998, and the volcanic activity of Mount Iwate, Japan. Geophys Res Lett 27(2):269-272. doi:10.1029/1999GL005439

Ohmi S, Hirahara K, Wada H, Ito K (2008) Temporal variations of crustal structure in the source region of the 2007 Noto Hanto Earthquake, central Japan, with passive image interferometry. Earth Planets Space 60(10):1069-1074

Okada Y (1992) Internal deformation due to shear and tensile faults in a half-space. B Seismol Soc Am 82(2):1018-1040

Poupinet G, Ellsworth WL, Frechet J (1984) Monitoring velocity variations in the crust using earthquake doublets: an application to the Calaveras Fault, California. J Geophys Res 89(B7):5719-5731. doi:10.1029/JB089iB07p05719

Research Group for Active Faults in Japan (1991) Active faults in Japan, rev edn. University of Tokyo Press, Tokyo, in Japanese with English abstract

Rubinstein JL, Beroza GC (2004) Evidence for widespread nonlinear strong ground motion in the MW 6.9 Loma Prieta earthquake. B Seismol Soc Am 94(5):1595-1608. doi:10.1785/012004009

Sawazaki K, Sato H, Nakahara H, Nishimura T (2009) Time-lapse changes of seismic velocity in the shallow ground caused by strong ground motion shock of the 2000 Western-Tottori earthquake, Japan, as revealed from coda deconvolution analysis. B Seismol Soc Am 99(1):352-366. doi:10.1785/0120080058

Sens-Schönfelder C, Wegler U (2006) Passive image interferometry and seasonal variations of seismic velocities at Merapi Volcano, Indonesia. Geophys Res Lett 33(21). doi:10.1029/2006gl027797

Shapiro NM, Campillo M, Stehly L, Ritzwoller MH (2005) High-resolution surfacewave tomography from ambient seismic noise. Science 307(5715):1615-1618. doi:10.1126/science.1108339

Snieder R, Grêt A, Douma H, Scales I (2002) Coda wave interferometry for estimating nonlinear behavior in seismic velocity. Science 295(5563):2253-2255. doi:10.1126/science.1070015

Ueno T, Saito T, Shiomi K, Enescu B, Hirose H, Obara K (2012) Fractional seismic velocity change related to magma intrusions during earthquake swarms in the eastern Izu peninsula, central Japan. J Geophys Res 117(B12). doi:10.1029/2012jb009580

Weaver RL, Hadziioannou C, Larose E, Campillo M (2011) On the precision of noise correlation interferometry. Geophys J Int 185(3):1384-1392. doi:10.1111/j.1365-246X.2011.05015.x

Wegler U, Sens-Schönfelder C (2007) Fault zone monitoring with passive image interferometry. Geophys J Int 168(3):1029-1033. doi:10.1111/ j.1365-246X.2006.03284.X

Wegler U, Lühr BG, Snieder R, Ratdomopurbo A (2006) Increase of shear wave velocity before the 1998 eruption of Merapi volcano (Indonesia). Geophys Res Lett 33(9). doi:10.1029/2006gl025928

Wegler U, Nakahara H, Sens-Schönfelder C, Korn M, Shiomi K (2009) Sudden drop of seismic velocity after the 2004 Mw6.6 mid-Niigata earthquake, Japan, observed with passive image interferometry. J Geophys Res 114(B6). doi:10.1029/2008jb005869

Yamada T, Yukutake Y, Terakawa T, Arai R (2015) Migration of earthquakes with a small stress drop in the Tanzawa Mountains, Japan. Earth Planets Space 67(1):175

Yamawaki T, Nishimura T, Hamaguchi H (2004) Temporal change of seismic structure around Iwate volcano inferred from waveform correlation analysis of similar earthquakes. Geophys Res Lett 31(24). doi:10.1029/2004gl021103 
Yukutake Y, Honda R, Harada M, Aketagawa T, Ito H, Yoshida A (2011) Remotelytriggered seismicity in the Hakone volcano following the 2011 off the Pacific coast of Tohoku Earthquake. Earth Planets Space 63(7):737-740. doi:10.5047/eps.2011.05.004

Yukutake Y, Miyazawa M, Honda R, Harada M, Ito H, Sakaue M, Koketsu K, Yoshida A (2013) Remotely triggered seismic activity in Hakone volcano during and after the passage of surface waves from the 2011 M9.0 Tohoku-Oki earthquake. Earth Planet Sc Lett 373:205-216. doi:10.1016/j.epsl.2013.05.004

Yukutake Y, Honda R, Harada M, Arai R, Matsubara M (2015) A magma-hydrothermal system beneath Hakone volcano, central Japan, revealed by highly resolved velocity structures. J Geophys Res 120(5):3293-3308. doi:10.1002/2014jb011856

\section{Submit your manuscript to a SpringerOpen ${ }^{\mathcal{O}}$ journal and benefit from:}

- Convenient online submission

- Rigorous peer review

- Immediate publication on acceptance

- Open access: articles freely available online

- High visibility within the field

- Retaining the copyright to your article

Submit your next manuscript at $\gg$ springeropen.com 